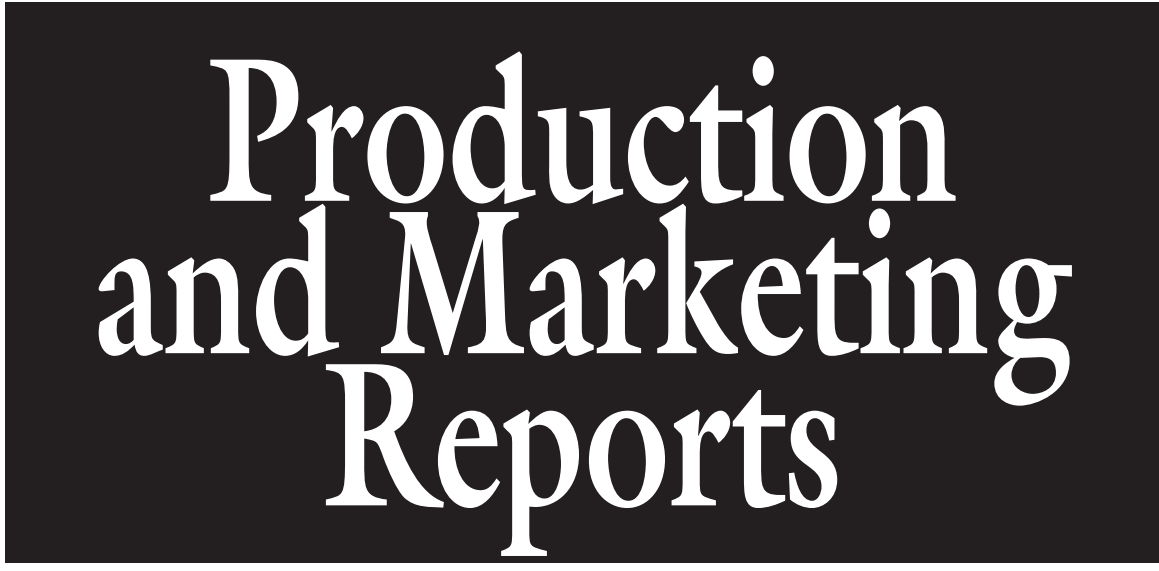

\title{
Discovering Niche Markets for Elderberry Juice in the United States
}

\author{
Phillip M. Mohebalian ${ }^{1,3}$, Mihaela M. Cernusca ${ }^{2}$, \\ and Francisco X. Aguilar ${ }^{1}$
}

AdDitional INDEX wORDs. Sambucus sp., perceptual map, conjoint analysis, consumer preferences, market segments

SumMARY. This study contributes to the limited research on elderberry (Sambucus sp.) marketing and consumer preferences by eliciting consumers' familiarity with elderberry products and identifying and profiling market segments for elderberry products. Results of a survey, distributed online to a sample of U.S. consumers, show one-third of respondents to be familiar with elderberry. The most common elderberry products sampled and purchased were juice, jelly, and wine. The consumer sample was divided into current and potential consumer groups. Healthconscious and less health-conscious consumer segments were identified within each group, composing four market segments in total. Current elderberry consumers (14\% of respondents) are on average younger, more educated, and less price sensitive than potential consumers. They strongly prefer locally produced juices and elderberry juice to other types of juices. For this category of consumers, elderberry juice products can be positioned as novelty products that are perceived to be healthier and more expensive than other comparable products. Including a qualified health claim on the label would reinforce the health benefits of elderberry products and potentially increase less health-conscious consumers' likelihood to purchase them. Market segments comprised of those who have not tried elderberry yet are characterized as appreciating locally produced products but as having greater price sensitivity than current consumers. Elderberry juice products can be introduced to these segments as value healthy products [similar to cranberry (Vaccinium macrocarpon)], emphasizing the health benefits and local origins while maintaining a lower price.

$\mathrm{T}$ The american elderberry ( Sambucus canadensis) is a fruitproducing shrub native to North America. European elderberry (Sambucus nigra) is found throughout Europe, Asia, and northern Africa. Commercial elderberry production is mainly found in Europe with the majority localized in

\footnotetext{
${ }^{1}$ Department of Forestry, University of Missouri, 203 ABNR Building, Columbia, MO 65211

${ }^{2}$ The Center for Agroforestry, University of Missouri, 203 ABNR Building, Columbia, MO 65211

${ }^{3}$ Corresponding author. E-mail: pmmrn3@mail.missouri.
} edu.
Denmark, Italy, Austria, and Germany. In the United States, elderberry is not as well known or used, therefore providing an opportunity for the growth of a new specialty crop along with its associated consumer markets. Most of the elderberry cultivars in North America (e.g., Adams I, Adams II, Johns,
York, Nova) were developed decades ago either at the New York Agricultural Experiment Station or at the Nova Scotia Experiment Station in Canada (Finn et al., 2008). Recently, scientists from the University of Missouri have introduced two new cultivars: 1) Wyldewood, a tall, vigorous elderberry plant that consistently produces high yields, is efficient to harvest and produces fruit well suited for processing (Byers et al., 2010); and 2) Bob Gordon, a productive cultivar adapted to the agronomic conditions in the midwestern United States that has outperformed the standard 'Adams II' and other genotypes in multiple studies (Byers and Thomas, 2011).

Elderberry has multiple uses. It has been widely cultivated for its fruit, as a medicinal plant, for ornamental purposes in parks and streets, and for erosion control. Elderberry flowers have diuretic, laxative, and anti-inflammatory properties. Used in infusions, they purportedly relieve allergy symptoms (Beaux et al., 1999; Mascolo et al., 1987; Uncini Manganelli et al., 2005). Berries are used to treat various disorders including colic, sinus congestion, constipation, diarrhea, sore throat, colds (Schapowal, 2007), and rheumatism (Novelli, 2003; Uncini Manganelli et al., 2005). Research indicates elderberries exhibit anti-inflammatory (Barak et al., 2002; Gorchakova et al., 2007), antiviral (Zakay-Rones et al., 1995, 2004), antioxidative (Pool-Zobel et al., 1999), and antibacterial (Chatterjee et al., 2004) properties. Given their antiviral properties, elderberries are commonly consumed for prophylaxis and treatment of influenza (Roschek et al., 2009; Zakay-Rones et al., 1995, 2004). According to the Interactive European Network for Industrial Crops and their Applications (IENICA), elderberry is also used in the cosmetic industry for facial toners and cleansers (IENICA, 2002). Pigments in elderberry juice are suitable for human consumption and can be used as food colorants (Charlebois et al., 2010).

According to Byers and Thomas (2005), most of the elderberries grown

\begin{tabular}{|c|c|c|c|}
\hline \multicolumn{4}{|l|}{ Units } \\
\hline $\begin{array}{l}\text { To convert U.S. to SI, } \\
\text { multiply by }\end{array}$ & U.S. unit & SI unit & $\begin{array}{l}\text { To convert SI to U.S., } \\
\text { multiply by }\end{array}$ \\
\hline $\begin{array}{r}29.5735 \\
1.6093\end{array}$ & $\begin{array}{l}\mathrm{floz} \\
\text { mile(s) }\end{array}$ & $\begin{array}{l}\mathrm{mL} \\
\mathrm{km}\end{array}$ & $\begin{array}{l}0.0338 \\
0.6214\end{array}$ \\
\hline
\end{tabular}


in the United States are harvested for processing markets. The fruit is used to produce elderberry wine, juice, jam, and jelly. The flowers are used to flavor wines, to make tea, or as a nonalcoholic cordial. Elderberry juice and concentrate are marketed as nutraceutical products. In 2009, elderberry in the United States, as a botanical dietary supplement, experienced an estimated $50 \%$ increase in sales from 2008 (Cavaliere et al., 2010). Elderberry juice and concentrate were the eighth best seller in the health and natural food stores sector in the United States, with estimated sales over \$6.8 million (Cavaliere et al., 2010). This was the second largest percent jump in sales of any botanical product in the 20 top-selling botanical dietary supplements within this marketing sector (Cavaliere et al., 2010). The increase in demand for antiflu products, in response to the "Influenza A" (H1Nl) virus outbreak, may partly explain this big jump in sales (Blumenthal et al., 2011). Research also indicates that the global market of nutraceuticals is forecasted to expand from 2010 to 2017 in the United States, Japan, United Kingdom, Spain, Italy, Germany, and France because of an increase in the elderly population and increasing awareness of, and preference for, preventive medicine (GBI Research, 2011).

The fruit juice and functional drink industry (e.g., fruit juice, sport and energy drinks, flavored waters, ready-to-drink tea and coffee) is growing because of an increasing number of health-oriented consumers switching from carbonated to functional drinks or other beverages. The fruit juice industry expanded at an annual rate of $10.4 \%$ and cumulative sales from 2006 through 2011 totaled $\$ 27$ billion, growing $8.9 \%$ in 2011 alone. According to Kaczanowska (2011), functional drinks and other new products heavily marketed to a young demographic drove this rapid revenue increase, though nationwide job losses and low consumer spending have weakened growth since 2008.

The literature about elderberry production and marketing in the United States is scarce. A comprehensive horticultural review was published in 2010 (Charlebois et al., 2010), which compiled literature from around the world about elderberry botany, horticulture, propagation, and uses. While production information is limited, data about consumer market preferences for particular products is even harder to find. Very little and only general information on the market potential and the production volumes of elderberries is available in the published research (Charlebois et al., 2010). A recent market study identified elderberry as a small, vertically integrated industry with high growth prospects, represented by a few players who primarily sell to early adopter customers and focus their efforts on creating consumer awareness for both the product and the industry (Cernusca et al., 2011). The market study by Cernusca et al. (2011) also identified favorable demand trends for elderberry products because of widespread knowledge of their health-boosting properties. Although elderberry has historically served medicinal and culinary purposes, it remains relatively unknown to a majority of consumers. Thus, it may be considered a new product for which market introduction strategies need to be developed. To realize enhanced profits, elderberry growers and supply chain members simultaneously need to attain a better understanding of the markets in which they operate (Cernusca et al., 2011 ).

Because markets are not homogeneous, market information will play a central role in the development of both introductory and growth strategies. Consumers differ in their values, needs, wants, constraints, beliefs, and incentives to act; hence, strategies require tailoring to particular market segments (Lilien et al., 2007). By segmenting consumer markets, firms can better understand their customers and target their marketing efforts more effectively. A study of consumer preferences aimed at better understanding tastes and purchasing behavior is therefore instrumental in providing strategic information to producers who can apply this knowledge to develop differentiation strategies. Strategies tailored to specific consumer market segments may lead to a more competitive position in the marketplace. By understanding the needs of consumers for each market segment, producers can continuously improve their responsiveness to such needs and build long-term financial success (Costa and Jongen, 2006).
This study contributes to the limited research base on elderberry market and consumer preferences. Specifically, it was designed to 1) assess consumers' familiarity with elderberry products, 2) assess preferences for alternative beverage options and identify market niches, and 3 ) identify and profile market segments for elderberry.

\section{Materials and methods}

Survey DeVElopMENT. A consumer survey was constructed following a multistep process. First, an exploratory survey was developed and administered to a convenience sample of local consumers in Columbia, MO. The exploratory survey helped establish consumer familiarity with elderberry products and select salient attributes that consumers seek in elderberry products. This information was used to design an online survey, which was refined during a subsequent focus group and pretested with a sample of local consumers. Methods followed to generate the final survey are detailed in Mohebalian (2011) and Mohebalian et al. (2011).

The final version of the survey was composed of five sections. The first section of the survey asked respondents about previous experiences in sampling or purchasing elderberry products (e.g., if they were familiar with elderberries or elderberry products; if they had sampled or purchased elderberry products in the past; the type of elderberry products they had sampled or purchased; locations where respondents sampled or purchased elderberry products). Frequency of consumption of elderberry products was measured on a seven-point scale, $(1=$ never, 2 = less than once per year, $3=$ 1-2 times per year, $4=3-5$ times per year, $5=6-11$ times per year, $6=1-3$ times per month, and $7=$ once per week or more).

The second section of the survey included questions that evaluated respondents' own lifestyle factors based on health-related attitudes and behaviors. Survey participants were asked to what extent they agree or disagree with the following statements: "I consider myself a health-conscious person," "I am knowledgeable of the health benefits of the foods I eat," and "locally grown foods are healthier than nonlocally grown foods." These questions were adapted from a study 
by Teratanavat and Hooker (2005) and were evaluated on a balanced five-point Likert scale $(1=$ strongly disagree, 2 = disagree, $3=$ neither agree nor disagree, $4=$ agree, $5=$ strongly agree). Two additional questions evaluated respondents' frequency of consumption of "foods that provide health-promoting or disease-fighting benefits beyond basic nutrition" and respectively frequency of shopping for "groceries from farmers markets, grocery stores, Internet/ mail order, and natural food stores."

The third section of the survey was designed to gauge consumers' perception of the current market for healthy beverages. Respondents were asked to evaluate the following products: acai (Euterpe oleracea) juice, apple (Malus domestica) juice, bottled green tea, bottled water, cranberry juice, grapefruit (Citrus paradisi) juice, and pomegranate (Punica granatum) juice. Their evaluations were based on how likely these products are to have a beneficial impact on their health and how expensive they perceive the products to be, based on their associated health benefits. Frequency of consumption for each of these products was also evaluated. Unlike the aforementioned products, elderberry juice is not a product currently existing in the market and therefore was not included in this evaluation.

The fourth section of the survey included conjoint analysis (CA). CA is a technique based on the premise that consumers can judge the value of hypothetical products (described by different attributes that make up product profiles) and choose the one that gives them the most utility (Carson et al., 1994; Green and Srinivasan, 1978, 1990). The technique has been applied to a number of horticultural products, including pears [Pyrus sp. (Gamble et al., 2006)], chestnuts [Castanea sp. (Aguilar et al., 2009, 2010)], fruit juices (Bonilla, 2010), bell peppers [Capsicum annuum (Frank et al., 2001)], peanuts [Arachis hypogaea (Nelson et al., 2005)], mandarins [Citrus reticulata (Campbell et al., 2006)], asparagus [Asparagus officinalis (Behe, 2006)], and apples (Baker, 1999). Preference elicitation in CA was done by using a choice-based conjoint model because it adds more realism to the product selection process. Using a choice-based instrument, respondents are asked to choose only one out of a bundle of hypothetical products, similar to a shopping decision where a product is bought out of an array of options (Aguilar et al., 2009, 2010; Bonilla 2010; Darby et al., 2008; Gamble et al., 2006).

By using a CA survey technique, we sought to better understand the real value consumers attach to certain attributes when making purchasing decisions (North and DeVos, 2002) and how these preferences differ for various market segments. The salient attributes (and corresponding levels) derived from the exploratory study of consumers included type of juice (elderberry, pomegranate, cranberry), price $(\$ 3, \$ 4, \$ 5)$, origin of cultivation (locally grown, grown in the United States, imported), and health claim on the label (yes, no). Nine pairs of hypothetical products (in Questions 1 to 9) were generated after applying a fractional factorial design to all possible combinations of attributes (Green and Srinivasan, 1978; Hensher et al., 2005). The respondents were presented in each question with three alternatives: two alternatives referring to product profiles with varying labels and one status quo option to be selected if none of the presented options were of interest. This status quo option represented the most popular option currently in the market (i.e., cranberry juice, $\$ 4$ price, made in the United States, and no health claim on the label) and was constant across the choice set. According to Mintel Group (2011), cranberry juice is the most popular juice product on the market if excluding orange and apple juice with over $40 \%$ of sample Americans over 18 having purchased cranberry for household consumption. Cranberry juice was also identified in the focus group discussion as being the most popular health juice drink consumed by participants (Mohebalian, 2011). The CA question presented to participants was "We would like you to imagine that you are now in a gourmet specialty store, shopping for a recyclable $12 \mathrm{oz}$ glass bottle of juice drink. You find that there are only three options of juice products to choose from. For the following questions please select the product that you would most likely purchase in this situation." The volume and characteristics of the juice container were identified during the focus group (Mohebalian, 2011). The presentation stimuli included pictures of juice bottles with labels containing a combination of the selected attributes and levels (Fig. 1).

The last section of the survey measured the demographic characteristics of respondents (i.e., gender, age, marital status, education level, how far they live from an urban area of at least 50,000 people, what state they currently live in, income, and ethnic background). The survey instrument received approval from the University of Missouri's Institutional Review Board before deployment.

SAMPle AND DATA COLleCtion. The survey instrument was deployed online in Aug. 2011 using Qualtrics (Qualtrics, Provo, UT). We targeted 500 U.S. respondents, 18 years of age or older with equal proportion of males and females. Study participants were comprised of a sample drawn from a U.S. panel of consumers administered by the international market intelligence agency, Survey Sampling International (SSI; Survey Sampling International, Shelton, CT). The agency maintains a pool of 800,000 online panelists in the United States. SSI sent out as many invitations and reminders as necessary to meet sample size specifications. Only one complete survey per participant was allowed, and reminders were sent every $24 \mathrm{~h}$ until the target number of complete surveys was achieved. The adequacy of the online sample to capture our target demographics was determined based on comparison of demographic information to U.S. census data. SSI applies the strictest quality processes to combat fraud and provide a representative sampling frame that minimizes bias and maximizes data integrity (SSI, 2012).

Data analysis. Various statistical tools were used to analyze the data collected. These included descriptive statistics, perceptual mapping, cluster analysis, and conditional logit regression for the CA. Descriptive analysis included common measures of centrality and dispersion and was performed to document the demographic characteristics of respondents, familiarity with elderberry, respondents' lifestyle, and their shopping habits.

Perceptual mapping was used to represent respondents' preference for alternative beverage options already 


\section{Question 1 (Which one would you purchase?)}
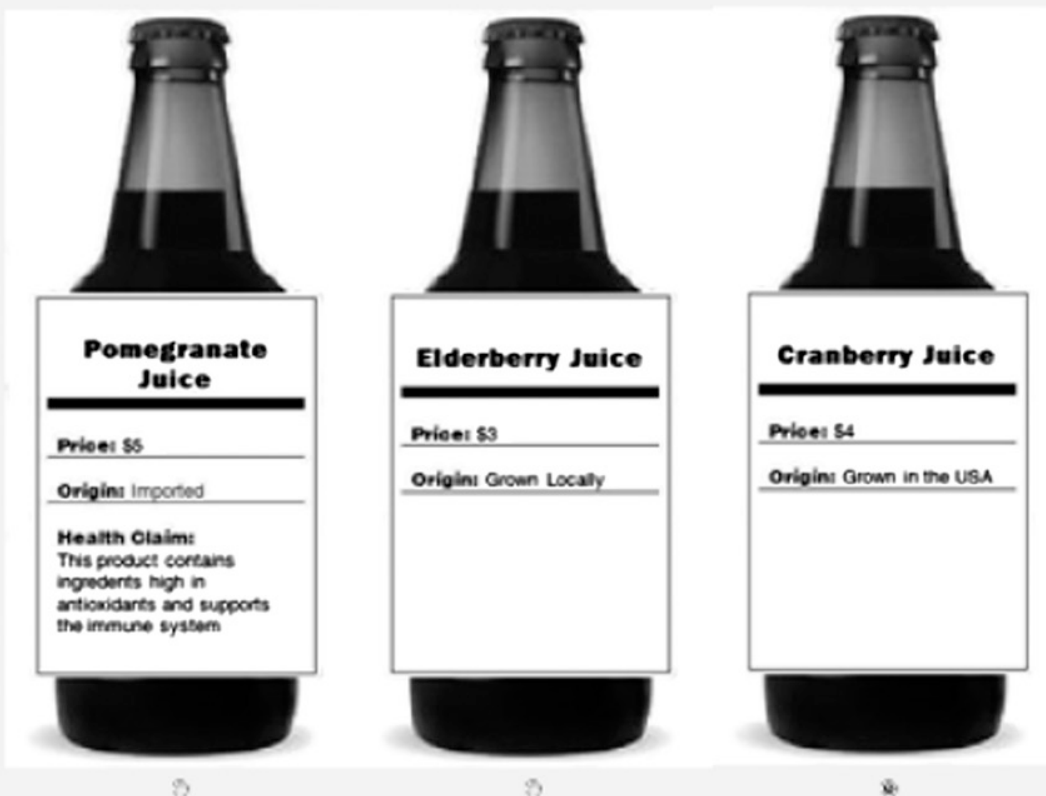

Question 2 (Which one would you purchase?)
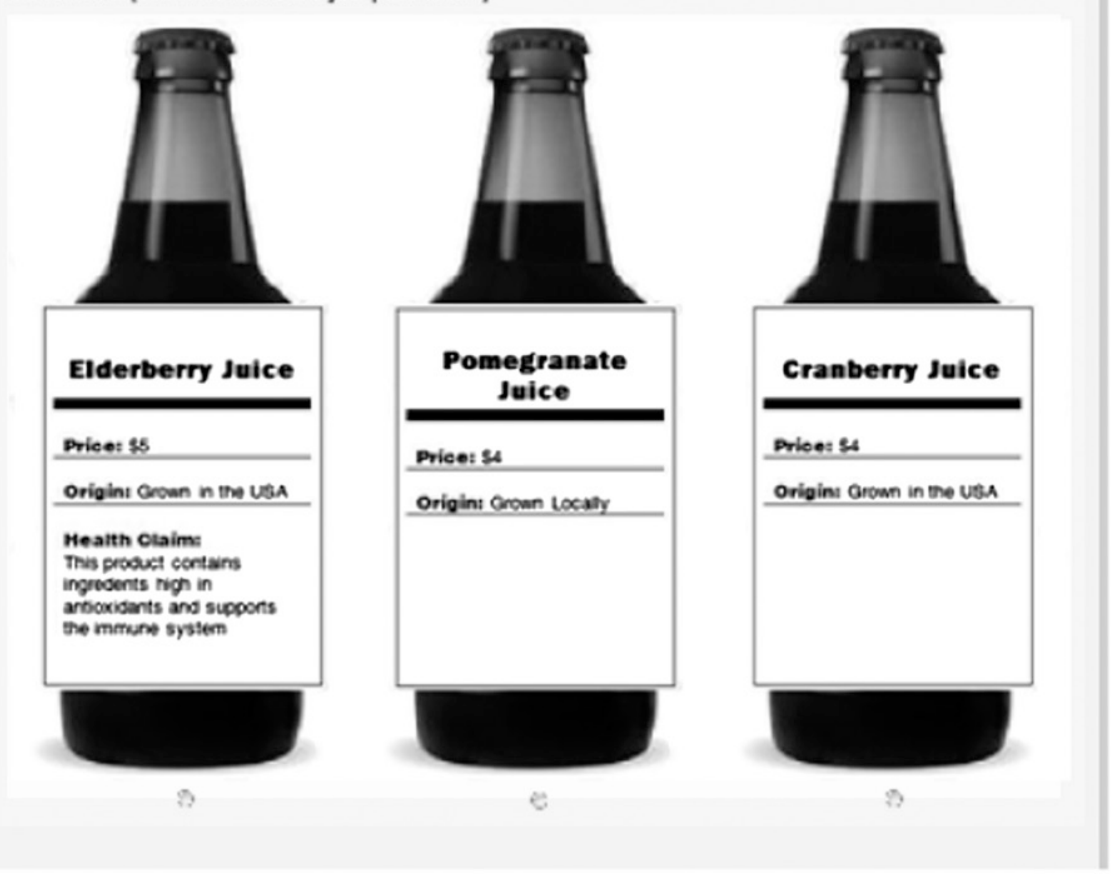

Fig. 1. Example of the conjoint analysis choice-based stimuli used to gather consumer preferences for elderberry juice in a survey distributed online in Aug. 2011. Health claims refer to "qualified health claims" as regulated by the U.S. Food and Drug Administration (FDA).

on the market (section 3 of the survey). Because elderberry juice is a new product to be introduced on the market, the perceptual map was used to describe the existing market (without elderberry). After identifying consumer segments, possible strategies of introducing elderberry juice into this existing market were recommended. Perceptual mapping is a marketing technique used to measure consumers' opinion of key product attributes. Maps are often used in product positioning and allow firms to develop strategies with better information of the market in which they are selling their products. According to Bagozzi et al. (1998), perceptual maps allow marketers to evaluate product strengths and weaknesses, market opportunities, and market evolution over time. The use of perceptual mapping is common in marketing research and is specifically useful in product development (Baourakis and Baltas, 2004; Scharl et al., 2005).

The perceptual map of the total sample of consumers was modeled using a three-dimensional bubble chart and represents consumer perceptions of a number of products sold in the beverage industry (Fig. 2). The horizontal axis represents the perceived average beneficial impact on personal health for given products (i.e., acai juice, apple juice, bottled green tea, bottled water, cranberry juice, grapefruit juice, and pomegranate juice) measured on a five-point scale anchored in 1 = strongly disagree and 5 = strongly agree. The vertical axis represents consumers' perceived current average market prices for the same products, measured on a fivepoint scale anchored in $1=$ very inexpensive and $5=$ very expensive. The perceptual map also represents the frequency of consumption of each product measured on a seven-point scale ranging from $1=$ never to $7=$ once per week or more. The mean value for the frequency of consumption is represented in the perceptual map by both the diameter of the bubble and the third value in the chart (Fig. 2).

To identify market segments among survey respondents, respondents were first split into two groups based on their past consumption of elderberry (consumed or not). A cluster analysis was applied on each group for the lifestyle variables presented in second section of the survey (Table 2 ). Cluster analysis helped sorting the raw data (i.e., consumers) to group them into clusters with a strong association within members of the same cluster but a weak one between clusters (Rencher, 2002). In marketing, cluster analysis is used for segmenting the market and determining target markets, product positioning, and new product development. The cluster analysis was performed using Stata 10 (StataCorp, College Station, TX) and created using " $k$ means" distance between individuals and their clusters average mean response. The analysis divided each sample into two 


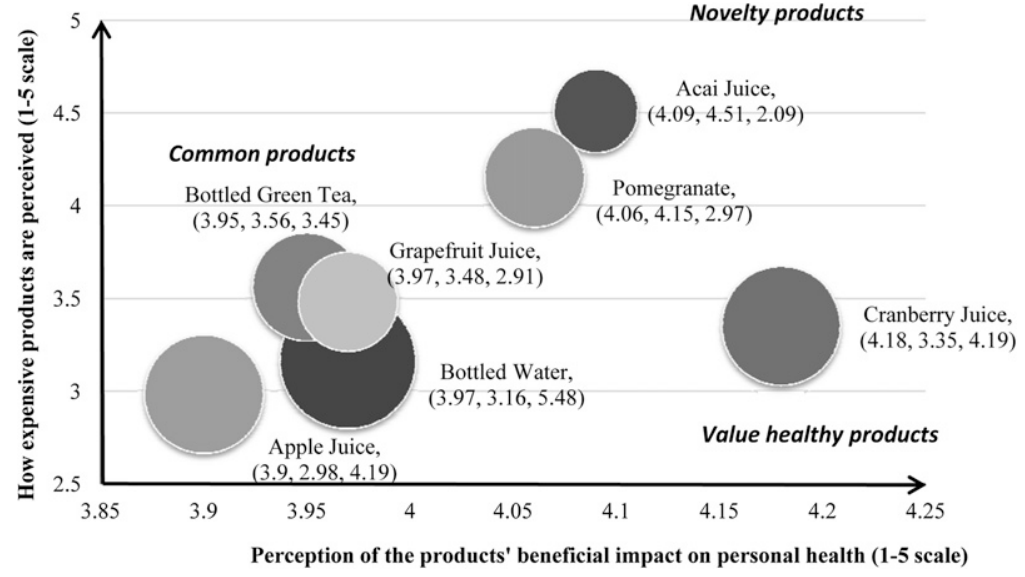

Fig. 2. Perceptual map that represents the health benefits of selected beverage products (horizontal axis, first value in the parenthesis for each product), how expensive the products are perceived in association with their health benefits (vertical axis, second value in the parenthesis for each product), and frequency of consumption (third value in the parenthesis for each product) as resulted from an online survey of consumer preferences for elderberry juice. Horizontal axis: $1=$ strongly disagree, 3 = neither agree nor disagree, $\mathbf{5}=$ strongly agree; vertical axis: $\mathbf{1}=$ very inexpensive, $\mathbf{5}$ = very expensive. Frequency of consumption of each product was measured on a seven-point scale $(1=$ never, $7=$ once per week or more $)$. The mean value for the frequency of consumption is represented by the diameter of each of the bubble and the third value in the chart.

predetermined clusters consisting of health-conscious and less health-conscious consumers. These categories were determined before the analysis, analogous to grouping identified during the exploratory research component of the study (Mohebalian, 2011) and with the purpose of comparing elderberry juice preferences between health-conscious and less healthconscious consumer segments. The four clusters that represent the four identified market segments were named: 1) "health-conscious current elderberry consumers," 2 ) "less health-conscious current elderberry consumers," 3) "health-conscious potential elderberry consumers," and $4)$ "less health-conscious potential elderberry consumers." The four clusters were described calculating $\mathrm{F}$ and $t$ tests to demographic characteristics. For each statistically significant Fstatistic (Table 2), pairwise $t$ tests were performed to determine whether there were statistically significant differences between individual group means. Statistically significant differences between the means of two groups are indicated in brackets. For example, respondents in segment l (sl) were found to be significantly different in terms of gender from consumers in segments 2 and 3 as denoted by (s2, s3) (Table 2).
The CA was analyzed using a conditional logistic regression (Aguilar et al., 2009, 2010; McFadden 1974, 1986 ) and applied to each cluster to further identify differences among consumer preferences and better describe market segments. The dependent variable used in the model was a binary response $(1=$ product chosen, 0 = product not chosen), which was collected for each of the nine product bundles. Within a bundle, consisting of two products and the status quo, respondents were allowed to choose only one juice, which was given a " 1 " as data were recorded and the other two nonchosen juices received a " 0 ." The predictors included the attributes defined in the CA: fruit type, origin and health claim as categorical variables, and price as a continuous variable. Odds ratios for all variables are interpreted as changes in the odds of a consumer choosing a product with a given attribute level over the base level. An odds ratio of 1 indicates that there is no difference in consumer preference between that level of the attribute and the base level. For a continuous variable (e.g., price), the value in the table represents the proportional change in the odds of selecting the product for every unit increase in price. A change in the odds of selecting a product is associated to an increase/decrease in the underlying utility an average consumer derives from selecting a particular product given its corresponding attributes (McFadden, 1986).

Relative importance of each attribute in determining consumer purchasing decisions was calculated based on methods described by Halbrendt et al. (1991) and applied in Harrison et al. (2002). The relative importance values were derived from the coefficients obtained for each attribute in the conditional logit model: $\mathrm{RI}_{i}=\left(\right.$ range $_{i} \times$ $100) / \Sigma$ (ranges), where $\mathrm{RI}_{i}$ is the relative importance for product attribute $i$. The range represents the difference in the highest and lowest coefficient value for each attribute, divided by the sum of all attribute ranges, multiplied by 100 .

\section{Results and discussion Sample demographic characteristics}

A total of 508 completed surveys were collected from respondents across the United States. Table l presents sample demographic characteristics (e.g., age, marital status, education, household income, ethnic background, urban/rural, location) compared with the 2000 U.S. Census data (U.S. Census Bureau, 2000). In general, data collected from the survey sample fit well with the estimates gathered for the U.S. population. Responses were evenly distributed between genders with $54.5 \%$ of surveys completed by female consumers. The age distribution was well balanced among respondents with one-quarter of respondents represented in each of the following age brackets: younger than 34 years old, 35 to 44 years old, 45 to 64 years old, and older than 64 years. Compared with the U.S. Census data, the 35 to 44 years and over 65 -year groups were slightly over-represented in our sample, while the 55- to 64-year group was under-represented. About half the respondents were high school graduates, while the other half held a college or graduate degree. The distribution of respondents based on income mirrors the U.S. population with $35 \%$ of respondents earning less than $\$ 35,000$ annually, 36\% between $\$ 35,000$ and $\$ 75,000$, and $19 \%$ more than $\$ 75,000$ (Table 1). Respondents from urban areas $(82 \%)$ were slightly over-represented in our sample as compared with $78 \%$ 
Table 1. Summary statistics of demographic characteristics of respondents to an online survey conducted in 2011 to assess preferences for elderberry juice and corresponding data for the 2000 U.S. Census.

\begin{tabular}{|c|c|c|}
\hline Total survey respondents & $\begin{array}{c}\text { Survey } \\
\text { sample }(\%)^{\mathrm{z}}\end{array}$ & $\begin{array}{l}\text { U.S Census } \\
2000(\%)^{\mathrm{y}}\end{array}$ \\
\hline \multicolumn{3}{|l|}{ Gender } \\
\hline Male & 45.50 & 49.10 \\
\hline Female & 54.50 & 50.90 \\
\hline \multicolumn{3}{|l|}{ Age (years) } \\
\hline $18-24$ & 6.50 & 14.54 \\
\hline $25-34$ & 18.10 & 21.26 \\
\hline $35-44$ & 24.60 & 12.25 \\
\hline $45-54$ & 19.50 & 20.18 \\
\hline $55-64$ & 3.50 & 12.98 \\
\hline 65 and Over & 27.80 & 18.79 \\
\hline \multicolumn{3}{|l|}{ Marital status } \\
\hline Married & 47.60 & 54.40 \\
\hline Unmarried & 52.40 & 45.60 \\
\hline \multicolumn{3}{|l|}{ Education } \\
\hline High school & 53.10 & 49.60 \\
\hline College degree & 34.10 & 21.80 \\
\hline Graduate degree & 10.40 & 8.90 \\
\hline Other & 2.40 & 19.70 \\
\hline \multicolumn{3}{|l|}{ Annual household income } \\
\hline Less than $\$ 35,000$ & 35.00 & 41.40 \\
\hline$\$ 35,000-\$ 50,000$ & 17.50 & 16.50 \\
\hline$\$ 51,000-\$ 75,000$ & 18.70 & 19.50 \\
\hline$\$ 76,000-\$ 100,000$ & 10.20 & 10.20 \\
\hline More than $\$ 100,000$ & 8.30 & 12.30 \\
\hline \multicolumn{3}{|l|}{ Ethnic background } \\
\hline African American & 10.00 & 12.60 \\
\hline Asian & 5.10 & 4.80 \\
\hline Hispanic/Latino & 4.90 & 16.30 \\
\hline Indian American & 1.60 & 0.90 \\
\hline White & 78.50 & 75.10 \\
\hline \multicolumn{3}{|l|}{$\begin{array}{l}\text { How far do you live from an urbanized area of at } \\
\text { least } 50,000 \text { people }\end{array}$} \\
\hline Urban (less than 30 miles from an urban area $)^{\mathrm{x}}$ & 82.00 & 77.62 \\
\hline Rural (more than 30 miles from an urban area) & 18.00 & 22.38 \\
\hline \multicolumn{3}{|l|}{ U.S. region } \\
\hline Western & 20.28 & 22.46 \\
\hline Central & 20.67 & 22.88 \\
\hline South & 40.16 & 35.62 \\
\hline Northeastern & 18.90 & 19.04 \\
\hline
\end{tabular}

${ }^{\mathrm{z}}$ Survey sample size $=508$.

y.S. Census Bureau (2000).

${ }^{x} 1$ mile $=1.6093 \mathrm{~km}$.

in the U.S. Census data, but this can be explained by the use of different definitions for urban/rural classification in our survey as compared with the definitions used by the U.S. Census Bureau (2000).

\section{Familiarity with elderberry}

Out of 508 respondents, $31 \%$ reported familiarity with elderberry products (i.e., have heard of elderberry) while the remaining $69 \%$ were not familiar. Of the respondents that have heard about elderberry and and jelly were mostly purchased at grocery stores and farmers markets, elderberry wine at grocery stores and winery stores, and elderberry vitamin supplements in health food stores. Elderberry flower tea was consumed most frequently (average of 5.82 on a scale of $1=$ never to $7=$ once per week or more), followed by elderberry syrup (5.5), elderberry concentrate (5.4), elderberry vitamin supplements (5.38), elderberry juice (5.34), elderberry wine (5.21), and elderberry jelly (4.77).

\section{Respondents' lifestyle and shopping habits}

Sixty-eight percent of respondents considered themselves health conscious (i.e., answered agree or strongly agree to the statement "I consider myself a health-conscious person"). Seventy-one percent agree or strongly agree with the statement "I am knowledgeable of the health benefits of the foods I eat." Almost half of respondents (47\%) agreed or strongly agreed that locally grown foods are healthier than nonlocally grown foods. When asked about foods that promote healthy or disease-fighting benefits beyond basic nutrition, $22 \%$ of respondents consume them one to three times per month and another $45 \%$ once per week or more.

Respondents reported they shop for groceries most frequently at grocery stores $(65 \%$ shop at grocery stores once per week or more, while $9 \%$ shop at farmers markets, $5 \%$ at health food stores, and 3\% over the Internet with the same frequency). Sixty-nine percent of respondents never shop for groceries over the Internet, $41 \%$ never shop at health food stores, and 23\% never shop at farmers markets.

\section{Consumers' preference for alternative options of beverages (perceptual map)}

The perceptual map of the total elderberry products, $55 \%$ (17\% of the total sample) have tasted or sampled elderberry products. Seventyeight percent of respondents that had sampled elderberry ( $14 \%$ of the total sample) also purchased elderberry products. Elderberry wine (42\%), elderberry jelly (41\%), and elderberry juice $(41 \%)$ were the products most sampled by respondents. Elderberry juice (35\%), elderberry jelly (31\%), and elderberry wine $(24 \%)$ were also reported as the most frequently purchased products. Elderberry juice sample of consumers is presented in Fig. 2. Products means for each dimension were compared two at the time using paired-samples $t$ tests. Differences in product means with a Type-I error probability value less than 0.05 were deemed statistically significant (i.e., $P>0.05$ suggests differences in consumers' preferences were not statistically different). Examples of nondifferences in product preferences can be seen in Fig. 2 for the perceived health benefits of acai 
Table 2. Cluster analysis results on two samples of respondents (those who consumed elderberry in the past and labeled current elderberry consumers, and those who have not consumed elderberry in the past labeled potential elderberry consumers) who completed the online survey on consumer preferences for elderberry juice $(N=508)$.

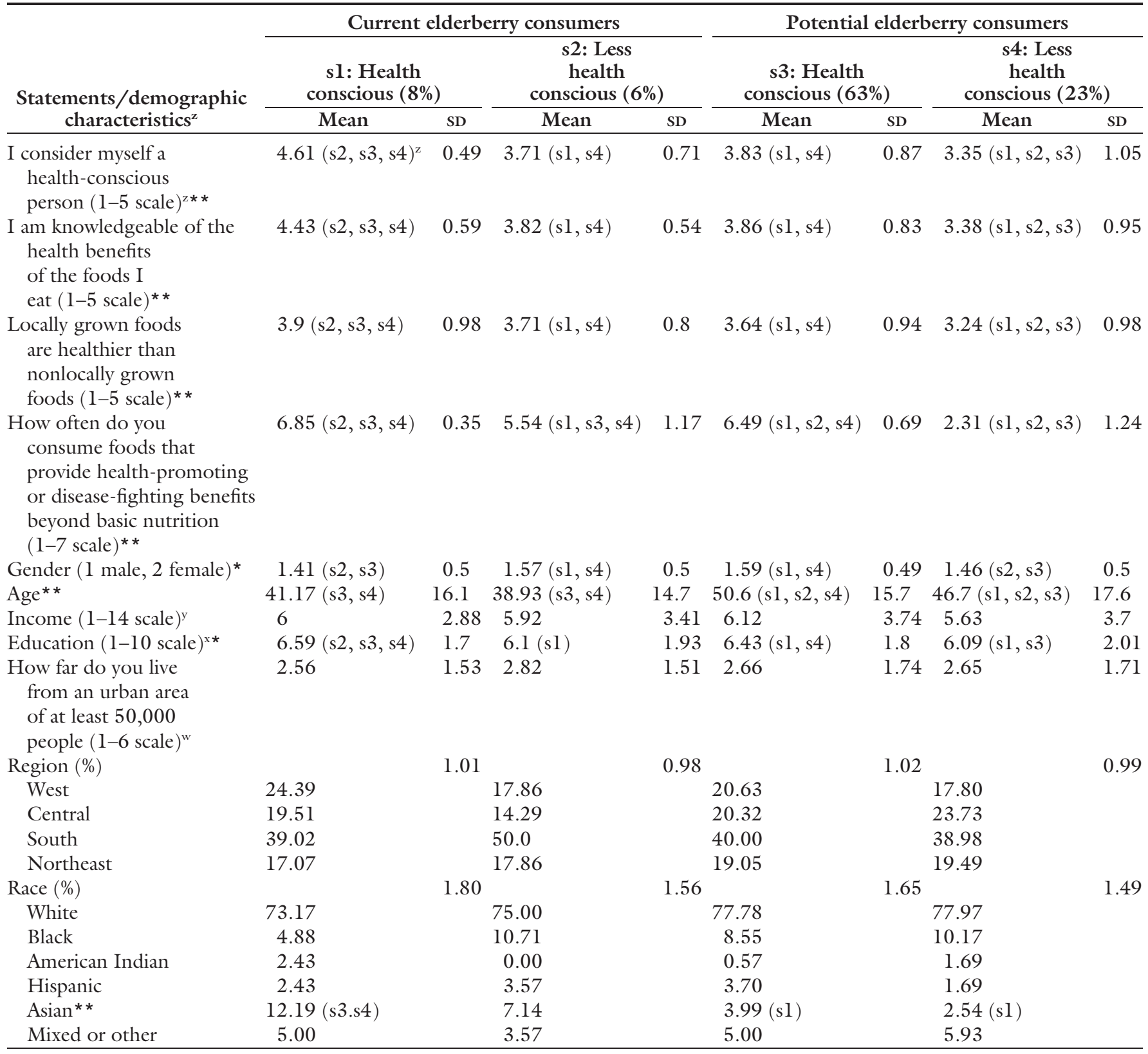

${ }^{\mathrm{z}} \mathrm{A}$ significant $\mathrm{F}$ test at $5 \%$ level of probability is indicated by ** after the variable name and a significance at $10 \%$ is indicated by * . Statistically significant differences between the means of two groups are indicated in parentheses. For example, respondents in segment 1 (sl) were found to be significantly different in terms of gender from consumers in segments 2 and 3 as denoted by (s2, s3).

${ }^{\mathrm{y}} \mathrm{l}=$ less than $\$ 10,000 ; 2=\$ 10,000-\$ 14,999 ; 3=\$ 15,000-\$ 24,999 ; 4=\$ 25,000-\$ 34,999 ; 5=\$ 35,000-\$ 49,999 ; 6=\$ 50,000-\$ 74,999 ; 7=\$ 75,000-\$ 99,999 ; 8=\$ 100,000-$ $\$ 124,999 ; 9=\$ 125,000-\$ 144,999 ; 10=\$ 155,000-\$ 174,999 ; 11=\$ 175,000-\$ 139,999 ; 12=\$ 200,000-\$ 224,999 ; 13=\$ 225,000-\$ 249,999 ; 14=\$ 250,000$ and $m o r e$.

${ }^{\mathrm{x}} \mathrm{l}=$ ninth grade or lower; $2=10$ th grade; $3=11$ th grade; $4=$ high school diploma; $5=$ some college credit but less than 1 year; $6=1$ or more years of college, no degree; $7=$ associate degree; $8=$ bachelor degree; $9=\mathrm{MS}, \mathrm{MBA}, \mathrm{MD}$, or $\mathrm{PhD} ; 10=$ professional degree.

${ }^{\mathrm{w}} \mathrm{l}=\mathrm{I}$ am in an urban area, $2=$ less than 5 miles, $3=5-9$ miles, $4=10-29$ miles, $5=30-50$ miles, $6=$ more than 50 miles, 1 mile $=1.6093 \mathrm{~km}$.

juice (4.09), cranberry juice (4.18), and pomegranate juice (4.06). In analyzing the means of how expensive consumers find the seven products and how often they purchase them, with two exceptions, all other means were found significantly different. The first exception was the grapefruit juice (3.48) and bottled green tea (3.56) as they occupy a similar conceptual space in reference to how expensive consumers find them. Second, when looking at the frequency of consumption, apple juice appears to have the same frequency of consumption as cranberry juice (4.19).

The perceptual map (Fig. 2) visually suggests three possible product groupings. In the lower left corner of the map, bottled green tea, grapefruit juice, bottled water, and apple juice, perceived as occupying similar conceptual space, were grouped under "common products." These products were perceived as both having lower health benefits and being less expensive than the other two groups. Pomegranate juice and acai juice were perceived as being the most expensive juice types, with higher beneficial impact 
Table 3. Conditional logistic results applied to each market segment (sl-s4) based on a sample of consumers who completed the online survey on preferences for elderberry juice.

\begin{tabular}{|c|c|c|c|c|c|c|c|c|}
\hline \multirow[b]{3}{*}{ Juice attributes and levels } & \multicolumn{4}{|c|}{ Current elderberry consumers } & \multicolumn{4}{|c|}{ Potential elderberry consumers } \\
\hline & \multicolumn{2}{|l|}{$\begin{array}{l}\text { sl: Health } \\
\text { conscious }^{\mathrm{z}}\end{array}$} & \multicolumn{2}{|c|}{$\begin{array}{l}\text { s2: Less health } \\
\text { conscious }^{\mathrm{y}}\end{array}$} & \multicolumn{2}{|l|}{$\begin{array}{l}\text { s3: Health } \\
\text { conscious }^{\mathrm{x}}\end{array}$} & \multicolumn{2}{|c|}{$\begin{array}{l}\text { s4: Less health } \\
\text { conscious }^{w}\end{array}$} \\
\hline & $\begin{array}{c}\text { Coefficient } \\
(\mathrm{SE})\end{array}$ & $\begin{array}{l}\text { Odds } \\
\text { ratio }\end{array}$ & $\begin{array}{c}\text { Coefficient } \\
(\mathrm{SE})\end{array}$ & $\begin{array}{l}\text { Odds } \\
\text { ratio }\end{array}$ & $\begin{array}{c}\text { Coefficient } \\
(\mathrm{SE})\end{array}$ & $\begin{array}{l}\text { Odds } \\
\text { ratio }\end{array}$ & $\begin{array}{c}\text { Coefficient } \\
(\mathrm{SE})\end{array}$ & $\begin{array}{l}\text { Odds } \\
\text { ratio }\end{array}$ \\
\hline Juice type & \multicolumn{8}{|c|}{ Base level: Pomegranate juice } \\
\hline Elderberry juice & $0.091(0.134)$ & 1.095 & $0.031(0.160)$ & 1.031 & $-0.346^{*}(0.056)$ & 0.707 & $-0.325^{*}(0.095)$ & 0.723 \\
\hline Origin of production & \multicolumn{8}{|c|}{ Base level: Imported } \\
\hline Local & $1.501 *(0.219)$ & 4.488 & $1.249 *(0.245)$ & 3.485 & $1.288 *(0.082)$ & 3.626 & $0.839 *(0.134)$ & 2.315 \\
\hline United States & $1.223^{*}(0.227)$ & 3.398 & $0.708 *(0.256)$ & 2.030 & $0.924 *(0.088)$ & 2.521 & $0.652 *(0.140)$ & 1.921 \\
\hline Health claim & \multicolumn{8}{|c|}{ Base level: Without bealth claim } \\
\hline With health claim & $0.682 *(0.138)$ & 1.979 & $0.489 *(0.163)$ & 1.631 & $0.916 *(0.057)$ & 2.498 & $0.542 *(0.092)$ & 1.720 \\
\hline
\end{tabular}

than the common products, and were grouped in a class named "novelty products." Finally, cranberry was perceived as being both relatively inexpensive and the product with the greatest health benefits and its class was named "value healthy products."

\section{Market segments}

The results of the cluster analysis are presented in Table 2, and the results of the conditional logit model applied to each cluster are presented in Table 3. The four aforementioned market segments are described below:

Current versus potential ELDERBERRY CONSUMERS. Respondents who had purchased elderberry products (current elderberry consumers) scored higher means for all health-related characteristics (Table 2). At the average, this group is younger and more educated than people that have not yet purchased elderberry (i.e., potential elderberry consumers) ( Table 2). Current elderberry consumers prefer elderberry juice to pomegranate juice, while consumers who have not previously purchased elderberry prefer cranberry juice to pomegranate juice when controlling for all other variables. Current elderberry consumers have a high preference for local and U.S. produced juices and are less price sensitive while potential elderberry consumers have a strong preference for a health claim to appear on the product label (Table 3 ).
Segment 1: Health-conscious CURRENT ELDERBERRY CONSUMERS. This market segment was identified as being health conscious with mean responses to health-related questions significantly greater than the responses of the other three groups. The segment represents $8 \%$ of the sample. Respondents in this segment were more likely to be male than female and significantly different from segments 2 and 3, 41 years old in average, earning in average between $\$ 50,000$ and $\$ 75,000$ per year. Respondents in this segment had received the highest level of education of all four segments, with the average education level being equivalent to an associate's degree. As a group, they lived on average between 5 and 9 miles from an urban area and have the higher proportion of Asian people, significantly different from respondents in segments 3 and 4 (Table 2). The odds for consumers in segment 1 to choose locally produced juices were 4.5 times higher than imported, all other variables being constant. The odds of selecting U.S. produced juices were 3.4 times higher than imported. For this group of consumers, the odds of selecting a juice with a health claim were almost two times higher than selecting a product without a health claim. Regarding the price impact, for every unit increase in the price of a given juice product, the odds of a consumer in segment 1 purchasing that product decreases by $45 \%$ when controlling for all other variables (Table 3 ).

Segment 2: Less healthCONSCIOUS CURRENT ELDERBERRY CONSUMERs. This market segment was identified as having mean response to health-related questions significantly lower than the health-conscious segment in the current elderberry consumers group (segment 1) and represents $6 \%$ of the sample size. This segment was more likely to be composed of females than males, 39 years of age on average. The respondents in this segment were also found to have less education than the healthconscious elderberry consumer segment, with the average respondent in this group completing 1 year of college or less. They were likely to live in average 5 to 9 miles from an urban area and earned between $\$ 50,000$ and $\$ 75,000$ per year (Table 2). Consumers in segment 2 strongly prefer local and U.S. produced juices (odds ratio 3.485 for local and 2.030 for United States) and were 1.6 times more likely to select a juice containing a health claim than a product with no health claim. For every \$1 increase in the price of a given juice product, the probability of a consumer in segment 2 purchasing that product decreases by $35 \%$, when controlling for all the other variables (Table 3).

Segment 3: Health-conscious POTENTIAL ELDERBERRY CONSUMERS. The largest segment $(63 \%$ of the 
sample size) was identified as being health conscious with their mean response to health-related questions significantly greater than the less health-conscious segment in the potential elderberry consumer group. Respondents in this segment were more likely to be female than male and older with the average respondent being $5 \mathrm{l}$ years old. The average respondent in this group has completed 1 year of college or less, lived 5 to 9 miles or less from an urban area, and made between $\$ 50,000$ and $\$ 75,000$ per year (Table 2 ). Consumers in segment 3 prefer cranberry juice to pomegranate juice (odds ratio 1.391) and pomegranate juice to elderberry juice (odds ratio 0.707 with pomegranate juice as base level). Consumers in this segment are very price sensitive. For every $\$ 1$ increase in the price of a juice product, the odds of a consumer in segment 3 purchasing that product decreases by $58 \%$ when controlling for all other variables. They also strongly prefer locally produced (3.626 odds ratio) and U.S. produced juices (2.521 odds ratio) as compared with imported juices (Table 3 ).

Segment 4: Less healthCONSCIOUS POTENTIAL ELDERBERRY CONSUMERs. This market segment was identified as being less health conscious in the potential elderberry consumer group and represented 23\% of the total sample size. Respondents in segment 4 were more likely to be male than female, 47 years old on average, and received less education than respondents in segments 1 and 3 averaging less than 1 year of college with no degree. Respondents in this segment earned between $\$ 50,000$ and $\$ 75,000$ per year and lived 5 to 9 miles from an urban area (Table 2 ). The less health-conscious potential elderberry consumers had preference for cranberry juice (the odds of purchasing cranberry juice are 1.6 times higher than purchasing pomegranate juice). They preferred locally produced juices 2.3 times more than imported. They preferred juice with a health claim but comparatively less than consumer in a health-conscious segment. They were also price sensitive with the probability of purchasing a $\$ 1$ higher in price juice decreasing by $53 \%$ (Table 3 ).

To understand which attribute had more influence on consumer choice, the relative factor of importance of the attributes was calculated for each of the market segments (Table 4). For the total sample, price was found as being the most important attribute in making a choice among various juice products $(38.5 \%)$. The importance of the other attribute ranged as follows: origin of production second $(29.8 \%)$, health claim third $(19.1 \%)$, and fruit type the last one $(12.6 \%)$. When looking at market segments, current elderberry consumers (segments 1 and 2) were more influenced by origin of production when making a decision to purchase juice than price.

The results of this study validate the importance that consumers place on local and U.S.-made products over imported products. The high value that consumers place on local foods has been reported in a number of marketing studies by Aguilar et al. $(2009,2010)$ in Missouri, Changyan and Tong (2009) in Minnesota, Gallons et al. (1997) in Delaware, Girauld et al. (2005) in New England, Jekanowski et al. (2000) in Indiana, and Patterson et al. (1999) in Arizona. In our study, health claims were found to be an important factor in the purchase decision for consumers purchasing juice products with consumers consistently preferring products with health claims over products without health claims. The growing popularity of foods that promote health benefits is well supported in diverse marketing studies including Ghazanfar and Camire (2002), Kozup et al. (2003), Robinson and Smith (2003), and Verbeke (2005).

If looking at the potential elderberry consumer group who represents $86 \%$ of respondents, differences between health-conscious and less health-conscious consumers support the results that health-conscious consumers are more likely to be female, older, more educated, and higher income earners. Similarly, Kraft and Goodell (1993) found that individuals who lead a "wellness-oriented" lifestyle are concerned with nutrition, wellness, stress, and their environment. They accept responsibility for their health and are excellent consumers for health-related products and services.

\section{Conclusions and recommendations}

This study contributes to the limited research on elderberry marketing and consumer preferences by garnering consumers' familiarity with elderberry products, and identifying and profiling market segments for elderberry products. A third of the U.S. sample used in this study indicated familiarity with elderberry. Of those individuals familiar with elderberry, 55\% had sampled elderberry products. In addition, $78 \%$ of those individuals who had sampled elderberry products also purchased them. The most common elderberry products sampled and purchased were juice, jelly, and wine.

A perceptual map of beverage products graphically identified three categories of products based on how healthy and how expensive they were perceived by consumers. The product categories were labeled as: 1) common products (bottled water, green tea, apple juice, and grapefruit juice), 2) novelty products (pomegranate juice and acai juice), and 3 ) value healthy products (cranberry juice). Cranberry juice was perceived to be the healthiest, not very

Table 4. Relative factor importance of attributes used in a conjoint analysis on four consumer segments (s1-s4) as resulted in a consumer preference for elderberry juice study

\begin{tabular}{|c|c|c|c|c|c|}
\hline \multirow[b]{3}{*}{ Attribute } & \multirow{3}{*}{$\begin{array}{c}\text { Total } \\
\text { sample }\end{array}$} & \multicolumn{2}{|c|}{$\begin{array}{l}\text { Current elderberry } \\
\text { consumers }\end{array}$} & \multicolumn{2}{|c|}{$\begin{array}{c}\text { Potential elderberry } \\
\text { consumers }\end{array}$} \\
\hline & & $\begin{array}{l}\text { sl: Health } \\
\text { conscious }\end{array}$ & $\begin{array}{c}\text { s2: Less } \\
\text { health } \\
\text { conscious }\end{array}$ & $\begin{array}{l}\text { s3: Health } \\
\text { conscious }\end{array}$ & $\begin{array}{l}\text { s4: Less health } \\
\text { conscious }\end{array}$ \\
\hline & & \multicolumn{4}{|c|}{$(\%)$} \\
\hline Fruit type & 12.60 & 19.30 & 6.64 & 14.73 & 21.15 \\
\hline Origin of production & 29.80 & 35.93 & 45.09 & 28.06 & 22.81 \\
\hline Health claim & 19.10 & 16.33 & 17.65 & 19.96 & 14.73 \\
\hline Price & 38.49 & 28.45 & 30.61 & 37.25 & 41.32 \\
\hline
\end{tabular}


expensive, and with a high frequency of consumption.

To target consumers with specific product offerings according to their preferences, market segments were identified based on whether the respondents had prior experience in purchasing elderberry products and how healthy they rated their lifestyles. Within current and potential consumer groups, health-conscious and less health-conscious consumer segments were identified. A conditional logistic regression applied to each of the four market segments revealed details about attributes that influence purchasing decisions for each group.

Current elderberry consumers are younger, more educated, and less price sensitive than potential consumers. They strongly prefer locally produced juices. For this segment, elderberry juice products can be positioned as novelty products that are perceived by consumers as being healthy and more expensive than other products. Including a qualified health claim on the label would reinforce the health benefits of elderberry and would increase less health-conscious consumers' probability to purchase the products. Focusing on source of origin in advertising the elderberry juice product would take market share from products already in this category (pomegranate juice and acai juice) that cannot be produced locally throughout North America.

The market segments who have not tried elderberry are characterized by respondents with higher price sensitivity but who also value locally produced products. For them, elderberry juice products can be introduced as value healthy products (similar to cranberry), emphasizing the health benefits and local origin while maintaining a lower price. Another option is to blend locally produced elderberry juice with cranberry, which is already known and preferred by consumers in these segments to ease consumer acceptability.

Information gained through this study can be used both by the elderberry growers and by the juice producers to develop marketing strategies. By developing different products or developing different positioning strategies for different market segments, a firm can apply results from this study to stimulate growth in sales and gain competitive advantage.

\section{Literature cited}

Aguilar, F.X., M.M. Cernusca, and M.A. Gold. 2009. Exploratory assessment of consumer preferences for chestnut attributes in Missouri. HortTechnology 19(1):216-223.

Aguilar, F.X., M.M. Cernusca, M.A. Gold, and C.E. Barbieri. 2010. Frequency of consumption, familiarity and preferences for chestnuts in Missouri. Agrofor. Syst. 79(1):19-29.

Bagozzi, R.P., J. Antonio-Rosa, K.S Celly, and F. Coronel. 1998. Perceptual maps and product positioning. Prentice Hall, Upper Saddle River, NJ

Baker, A. 1999. Consumer preferences for food safety attributes in fresh apples: Market segments, consumer characteristics, and marketing opportunities. J. Agr. Resource Econ. 24(1): 80-97.

Baourakis, G. and G. Baltas. 2004. Brand management in the fruit juice industry, p. 153-157. In: P.M. Pardalos, A. Athanosios, and G. Baourakis (eds.). Supply chain and finance. World Scientific Publishing, River Edge, NJ.

Barak, V., S. Birkenfeld, T. Halperin, and I. Kalickman. 2002. The effect of herbal remedies on the production of human inflammatory and anti-inflammatory cytokines. Israel Medical Assn. J. 4(Suppl.11):919-922.

Beaux, D., J. Fleurentin, and F. Mortier. 1999. Effect of extracts of Orthosiphon stamineus Benth, Hieracium pilosella L., Sambucus nigra L. and Arctostaphylos uva-ursi (L.) Spreng. in rats. Phytother. Res. 13(3):222-225.

Behe, B.K. 2006. Conjoint analysis reveals consumers prefer long, thin asparagus spears. HortScience 41(5):12591262

Blumenthal, M., A. Lindstrom, M.E. Lynch, and P. Rea. 2011. Market report. Herb sales continue growth-up 3.3\% in 2010. HerbalGram 90:64-67.

Bonilla, T. 2010. Analysis of consumer preferences toward $100 \%$ fruit juice packages and labels. Louisiana State Univ., Baton Rouge, MS Thesis. 4 May 2012. <http://etd.lsu.edu/docs/available/ etd-07032010-194437/unrestricted/ BonillaThesis.pdf>.

Byers, P.L. and A.L. Thomas. 2005. Elderberry research and production in Missouri. New York Berry News 4: 14-17.

Byers, P.L. and A.L. Thomas. 2011. 'Bob Gordon' elderberry. J. Amer. Pomol. Soc. 65(2):52-55.
Byers, P.L., A.L. Thomas, and M. Millican. 2010. 'Wyldewood' elderberry. HortScience 45(2):312-313.

Campbell, B.L., R.G. Nelson, R.C. Ebel, and W.A. Dozier. 2006. Mandarin attributes preferred by consumers in grocery stores. HortScience 4l(3):664-670.

Carson, R.T., J. Louviere, D. Anderson, P. Arabie, D. Bunch, D. Hensher, R. Johnson, W. Kuhfeld, D. Steinberg, J. Swait, H. Timmermans, and J. Wiley. 1994. Experimental analysis of choice. Mktg. Lett. 5(4):351-368.

Cavaliere, C., P. Rea, M.E. Lynch, and M. Blumenthal. 2010. Herbal supplement sales rise in all channels in 2009. HerbalGram 86:62-65.

Cernusca, M.M., M.A. Gold, and L.D. Godsey. 2011. Using the Porter model to analyze the U.S. elderberry industry. Proc. 12th North American Agroforestry Conf., Athens, GA, 4-9 June 2011. p. 191-200.

Changyan, Y. and C. Tong. 2009. Organic or local? Investigating consumer preference for fresh produce using a choice experiment with real economic incentives. HortScience 44(2):366-371.

Charlebois, D., P. Byers, C.E. Finn, and A.L. Thomas. 2010. Elderberry: Botany, horticulture, potential. Hort. Rev. 37: 213-280

Chatterjee, A., T. Yasmin, D. Bagchi, and S.J. Stohs. 2004. Inhibition of Helicobacter pylori in-vitro by various berry extracts, with enhanced susceptibility to clarithromycin. Mol. Cell. Biochem. 265: 19-26.

Costa, A.I.A. and W.M.F. Jongen. 2006. New insights into consumer-led food product development. Trends Food Sci. Technol. 17:457-465.

Darby, K., M.T. Batte, S. Ernst, and B. Roe. 2008. Decomposing local: A conjoint analysis of locally produced foods. Amer. J. Agr. Econ. 90(2):476-486.

Finn, C.E., A.L. Thomas, P.L. Byers, and M. Kemal. 2008. Evaluation of american (Sambucus canadensis) and european ( $S$. nigra) elderberry genotypes grown in diverse environments and implications for cultivar development. HortScience 43(5):1385-1391.

Frank, C.A., R.G. Nelson, and E.H. Simonne. 2001. Consumer preferences for color, price, and vitamin $\mathrm{C}$ content of bell peppers. HortScience 36(4):785-800.

Gallons, J., U.C. Toensmeyer, J.R. Bacon, and C.L. German. 1997. An analysis of consumer characteristics concerning direct marketing of fresh produce in Delaware: A case study. J. Food Distrib. Res. 28: 98-106. 
Gamble, J., S.R. Jaeger, and F.G. Harker. 2006. Preferences in pear appearance and response to novelty among Australian and New Zealand consumers. Postharvest Biol. Technol. 41(1):38-47.

GBI Research. 2011. Nutraceuticals market to 2017-Food additives such as omega-3 fatty acids, probiotics, soy and energy drinks to perform strongly. 4 May 2012. <http://www.marketresearch. com/GBI-Research-v3759/NutraceuticalsFood-Additives-Omega-Fatty-6511079/>.

Ghazanfar, S. and M.E. Camire. 2002. Influence of health attitudes on the acceptability of cranberry juice. J. Food Sci. 67(9):3497-3501.

Girauld, K.L., C.A. Bond, and J.J. Bond. 2005. Consumer preferences for locally made specialty food products across northern New England. Agr. Resource Econ. Rev. 34(2):204-216.

Gorchakova, T.V., I.V. Suprun, I.A. Sobenin, and A.N. Orekhov. 2007. Use of natural products in anticytokine therapy. Bul. Expt. Biol. Med. 143:316-319.

Green, P. and V. Srinivasan. 1978. Conjoint analysis in consumer research: Issues and outlook. J. Consum. Res. 5(2):103-123.

Green, P. and V. Srinivasan. 1990. Conjoint analysis in marketing: New developments with implications for research and practice. J. Mktg. 54(1):3-19.

Halbrendt, C., F. Wirth, and G. Vaughn. 1991. Conjoint analysis of the mid-Atlantic food-fish market for farm-raised hybrid striped bass. Southern J. Agr. Econ. 23(1):155-163.

Harrison, R.W., T. Stringer, and W. Prinyawiwatkul. 2002. An analysis of consumer preferences for value-added seafood products derived from crawfish. Agr. Resource Econ. Rev. 31(2):157-170.

Hensher, D.A., J.M. Rose, and W.H. Greene. 2005. Applied choice analysis. A primer. Cambridge University Press, Cambridge, UK.

Interactive European Network for Industrial Crops and their Applications. 2002. Elder. 8 Feb. 2012. <http://www.ienica. net/crops/elder.pdf $\geq$.

Jekanowski, M.D., D.R. Williams, II, and W.A. Schick. 2000. Consumers' willingness to purchase locally produced agricultural products: An analysis of an Indiana survey. Agr. Resource Econ. Rev. 29(8): 43-53.

Kaczanowska, A. 2011. Juice production in the U.S. IBIS World Industry Report 31211c. 7 Feb. 2012. <http://clients. ibisworld.com/industryus/default.aspx? indid $=287>$.
Kozup, J., E. Creyer, and S. Burton. 2003. Making healthful food choices: The influence of health claims and nutrition information on consumers' evaluation of packaged food products and restaurant menu items. J. Mktg. 67(2):19-34.

Kraft, F.B. and P.W. Goodell. 1993. Identifying the health conscious consumer. J. Health Care Mktg. 13(3):18-25.

Lilien, G.L., A. Rangaswamy, and A. De Bruyn. 2007. Principles of marketing engineering. Trafford Publishing, Victoria, BC, Canada.

Mascolo, N., G. Autore, F. Capasso, A. Menghini, and M. Palmira Fasulo. 1987. Biological screening of Italian medicinal plants for anti-inflammatory activity. Phytother. Res. 1:28-31.

McFadden, D. 1974. Conditional logit analysis of quantitative choice behavior, p. 105-142. In: P. Zarembka (ed.). Frontiers in econometrics. Academic Press, New York.

McFadden, D. 1986. The choice theory approach to market research. Mktg. Sci. 5(4):275-297.

Mintel Group. 2011. Juice and juice drinks: The market-U.S. 21 Feb. 2011. $<$ http://academic.mintel.com/sinatra/ oxygen_academic/search_results / show \&/display/id=590138/display $/$ $\mathrm{id}=542964>$.

Mohebalian, P. 2011. U.S. consumer preference for elderberry products. Univ. Missouri, Columbia, MS Thesis.

Mohebalian, P., M. Cernusca, and F. Aguilar. 2011. Consumer preference for elderberry juice products. Proc. 12th North American Agroforestry Conf., Athens, GA, 4-9 June 2011. p. 181-190.

Nelson, R.G., C.M. Jolly, M.J. Hinds, Y. Donis, and E. Prophete. 2005. Conjoint analysis of consumer preferences for roasted peanut products in Haiti. Intl. J. Consum. Stud. 29(3):208-215.

North, E. and R. DeVos. 2002. The use of conjoint analysis to determine consumer buying preferences: A literature review. J. Fam. Ecol. Consumer Sci. 30:32-39.

Novelli, S. 2003. Developments in berry production and use. Agr. Agri-Food Canada Bi-Weekly Bul. 16:5-6.

Patterson, P.M., H. Olofsson, T.J. Richards, and S. Sass. 1999. An empirical analysis of state agricultural product promotions: A case study of "Arizona Grown.” Agribusiness 15:179-196.

Pool-Zobel, B.L., A. Bub, N. Schroder, and G. Rechkemmer. 1999. Anthocyanins are potent antioxidants in model systems but do not reduce endogenous oxidative DNA damage in human colon cells. Eur. J. Nutr. 38:227-234.

Rencher, A.C. 2002. Methods of multivariate analysis. 2nd ed. Wiley, New York.

Robinson, R. and C. Smith. 2003. Associations between self reported health conscious consumerism, body mass index, and attitudes about sustainably produced foods. Agr. Human Values 20(2):177-187.

Roschek, B., R.C. Fink, M.D. McMichael, D. Li, and R.S. Alberte. 2009. Elderberry flavonoids bind to and prevent $\mathrm{HINI}$ infection in vitro. Phytochemistry $70(10)$ : 1255-1261.

Schapowal, A. 2007. Herbals for respiratory tract infection in pediatrics. Z. Phytother. 28(4):174-180.

Scharl, A., A. Dickinger, and J. Murphy. 2005. Diffusion and success factors of mobile marketing. Electron. Commerce Res. Appl. 4(2):159-173.

Survey Sampling International. 2012. SSI-Focusing on quality. 15 May 2012. <http://www.surveysampling.com/en/ General/about-us>.

Teratanavat, R. and N. Hooker. 2005. Exploring consumer valuation and preference heterogeneity for functional foods using a choice experiment: A case study of tomato juice containing Soy in Ohio. Proc. Amer. Agr. Econ. Assn. Annu. Mtg. Paper No. 19556. 21 May 2012. <http:// ageconsearch.umn.edu/bitstream / 19556/1/sp05te03.pdf>.

Uncini Manganelli, R.E., L. Zaccaro, and P.E. Tomei. 2005. Antiviral activity invitro of Urticadioica L., Parietariadiffusa M. et K. and Sambucus nigra L. J. Ethnopharmacol. 98:323-327.

U.S. Census Bureau. 2000. American fact finder. 8 Feb. 2012. <www.census.gov>.

Verbeke, W. 2005. Consumer acceptance of functional foods: Socio-demographic, cognitive and attitudinal determinants. J. Food Qual. Prefer. 16:45-57.

Zakay-Rones, Z., E. Thom, T. Wollan, and J. Wadstein. 2004. Randomized study of the efficacy and safety of oral elderberry extract in the treatment of influenza A and B virus infection. J. Intl. Med. Res. 32:132-140.

Zakay-Rones, Z., N. Varsano, M. Zlotnik, O. Manor, L. Regev, M. Schlesinger, and M. Mumcuoglu. 1995. Inhibition of several strains of Influenza Virus in Vitro and reduction of symptoms by an elderberry extract (Sambucus nigra L.) during an outbreak of Influenza B Panama. J. Altern. Complement. Med. 1(4):361-369. 